\title{
Simulation-based education involving online and on-campus models in different European universities
}

\author{
Neila Campos ${ }^{1}$, Maria Nogal ${ }^{2}$, Cristina Caliz ${ }^{3}$ and Angel A. Juan ${ }^{1 *}$ (1)
}

\author{
*Correspondence: ajuanp@uoc.edu \\ ${ }^{1}$ Universitat Oberta de Catalunya, \\ Barcelona, Spain \\ Full list of author information is \\ available at the end of the article
}

\begin{abstract}
Simulation-based education (SE) refers to the use of simulation software, tools, and serious games to enrich the teaching and learning processes. Advances in both computer hardware and software allow for employing innovative methodologies that make use of SE tools to enhance the learning experience. Moreover, thanks to the globalisation of e-learning practices, these educational experiences can be made available to students from different geographical regions and universities, which promotes the development of international and inter-university cooperation in education. This paper provides a review of recent works in the SE subject, with a focus on the areas of engineering, science, and management. It also discusses some experiences in SE involving different European universities and learning models. Finally, it also points out open challenges as well as noticeable trends.
\end{abstract}

Keywords: Simulation-based education, Higher education, E-learning, Engineering education

\section{Introduction}

Students in sciences, technology, engineering, and mathematics (STEM) have to deal with complex models of real-life systems. Regardless of whether these models refer to infrastructure systems, telecommunication networks, computer systems, or supply chains, STEM students need to receive specialised training to make informed decisions that affect complex systems with thousands of variables and interactions among their elements (Kutz et al. 2016). Moreover, real-life systems are usually subject to uncertainty and dynamism, some of which are generated by the human component of the system (Gruler et al. 2019). These aspects cannot be easily included in traditional analytical models, and typically require the use of simulation-based methodologies in coordination with other techniques, such as heuristic-based optimisation and machine learning methods. As pointed out in Juan et al. (2017), the use of simulation software, tools, and games facilitates the practical understanding of these complex systems and allows students to enhance their learning experience via the development of hands-on activities properly designed by their instructors.

It is well documented in the literature that intrinsic motivation in learning activities is strongly correlated with the outcome of the learning process (Gagne et al. 2005). By promoting direct participation of students in their knowledge building, simulation-based

(c) The Author(s), 2020 Open Access This article is distributed under the terms of the Creative Commons Attribution 4.0 International License (http://creativecommons.org/licenses/by/4.0/), which permits unrestricted use, distribution, and reproduction in any medium, provided you give appropriate credit to the original author(s) and the source, provide a link to the Creative Commons license, and indicate if changes were made. 
education (SE) incentives intrinsic motivation in the hands-on learning activities designed by the instructors and developed under their supervision and guidance. Learning practices based on the use of SE software, tools, and games are receiving the attention of academic and industrial partners, who see in SE a way to improve the training of their students and future employees. Figure 1 shows the evolution, in Google Scholar citations, of the term "simulation education" during the last two decades. Notice that the number of citations has evolved from 47 in the year 2000 to 968 in 2018. Also, the Holt-Winters exponential smoothing method (Montgomery et al. 2015) has been employed to complete a forecast for the next few years. According to this forecast, the number of citations will reach a level of approximately 1,200 by 2022 . Although many articles study the impact of SE methods in health-related degrees (Cant and Cooper 2017), works dealing with the topic under the view of the STEM are still scarce. This work aims at contributing to close this gap by focusing on the use of SE methods in STEM-related programmes. In this paper, we review some recent works on SE. From this review, several methodological practices, benefits, and challenges are identified.

The paper also describes several case studies on the use of SE in different European universities. These experiences include online as well as on-campus and blended learning models. They are based on our own long-term experience in the area and cover different universities, countries, and STEM degrees, as well as both blended and online learning modes. All in all, the main contributions of this paper are: (i) a review of recent works on SE applied to higher education; (ii) a series of examples on this usage, which covers different universities, countries, learning modes, and STEM programmes; and (iii) a summary of the main trends and existing barriers regarding the use of SE. The remaining of the paper is structured as follows: "Recent work on simulation-based education" section

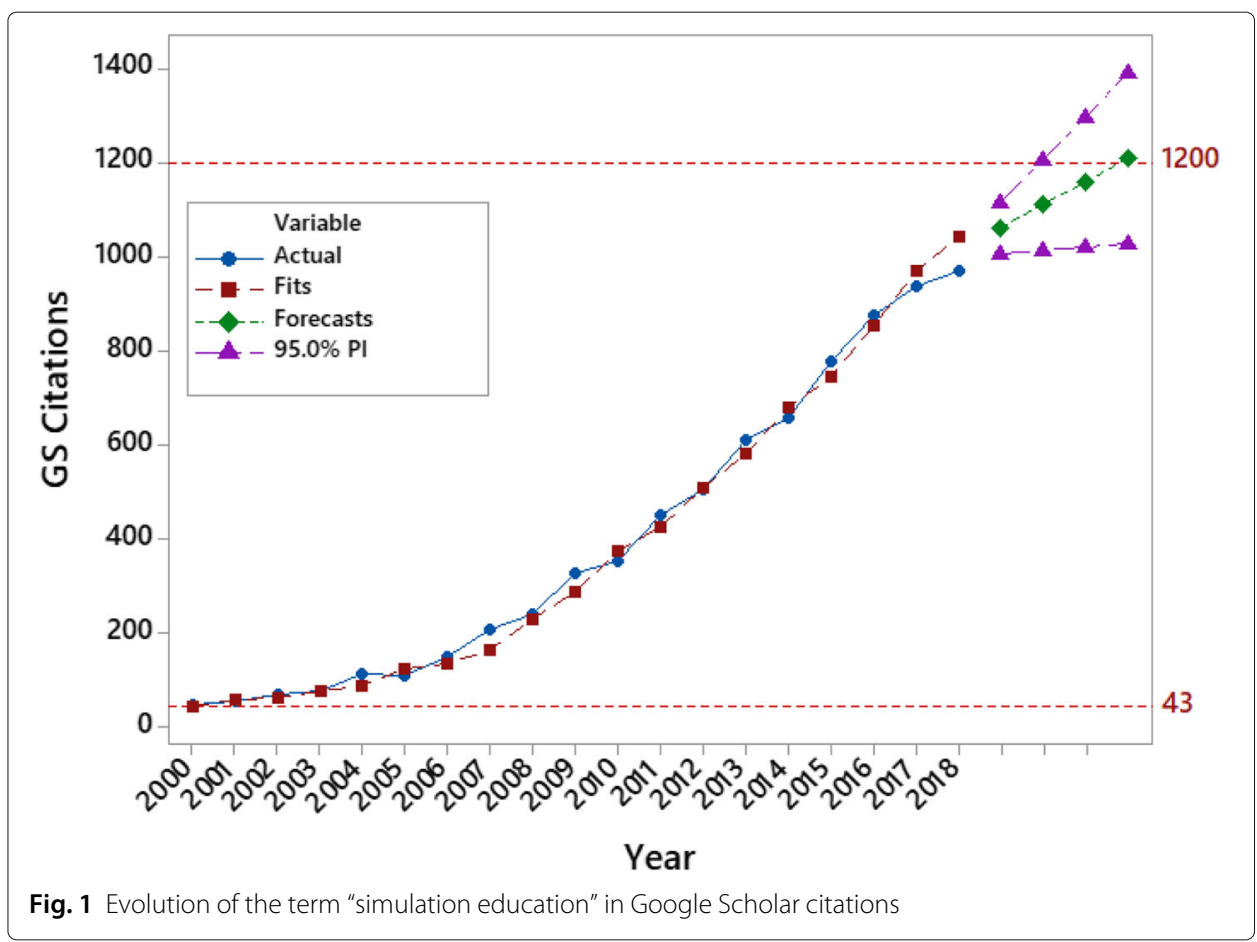


provides a short review of recent work on this topic; "Serious Games to Enrich the Learning Experience" section analyses how serious games can enrich the learning experience; "Benefits of simulation-based education" section focuses on the use of these learning strategies in the context of STEM degrees; "A Case Study at the Universidad de Cantabria (Spain)" section to "A case study at Trinity College Dublin (Ireland)" section describe some illustrative examples in different universities from Spain, Ireland, and Portugal; finally, "Conclusions and future work" section highlights the main findings of this work.

\section{Recent work on simulation-based education}

Seminal ideas on the use of simulation software, tools, and games to enhance the teaching and learning processes can be found in Schild (1968). In this section, however, we will pay special attention to recent publications. For reviews on previous work, the reader is referred to Nance (2000); Faria et al. (2009), and Bojičić-Petrov et al. (2012). Serving as a complement for traditional teaching methods, simulation software and serious games have been increasingly used as educational tools during the last decades (Costantino et al. 2012). The ongoing development of technology and programming languages have made simulation an advanced tool that reflects real situations with a high precision degree (Martin and McEvoy 2003). As noticed by Cai et al. (2016), SE and serious games are frequently overlapping concepts. On the one hand, a game is a competition between several players who aim at reaching a pre-established goal within a framework of rules and constraints. On the other hand, the term simulation usually refers to the computer-based representation of real-life situations. Although simulation is frequently employed to analyse complex systems, it can be also used to improve actors' knowledge and skills through experience. The simulation-based learning experience can be pedagogically designed as a competition-based problem where actors should accomplish a series of interactive exercises (Pasin and Giroux 2011). As indicated by Chapman and Martin (1995), the use of SE can enhance capabilities such as teamwork, problem-solving, decision making, or critical thinking. For instance, (Stanley and Latimer 2011) showed the effectiveness and suitability of simulation games in the nursing field, where students improved those skills in clinical practice scenarios. In some fields such as engineering, management, and science, SE has been used for training and learning purposes (Deshpande and Huang 2011). An extensive review on the use of serious games for management is provided in da Silva et al. (2019), including the analysis of previous studies on the subject. Likewise, an overview of the SE theoretical fundamentals can be found in Becker and Hermosura (2019).

In the context of STEM education, Riley (2012) remarks on the role of network simulation tools both in research and practical applications. However, this author considers that SE tools have not been fully incorporated as a key methodological element in networking courses. The author analyses a personal experience on the use of the popular $n s-3$ network simulator. Avramenko (2012) explains a case study in which business simulation is used as a mean to reduce the gap between theory and practice, thus enhancing students' skills for employability. Alnoukari et al. (2013) consider the importance of SE in the training of computer scientists. They discuss how simulation-based courses can provide students with a training capacity that is not easy to reach by just using traditional laboratories. Tvrdoň and Jurásková (2015) focus on the use of SE to teach courses on logistics and supply chain management. They describe their own experience in using the software Witness 
to facilitate the hands-on learning of advanced logistics concepts. Perera and Rupasinghe (2015) discuss the lack of in-house supply chain experts in many enterprises. Accordingly, the authors introduce a case study regarding the use of commercial simulation software to train professionals in supply chain dynamics. Frantzén and Ng (2015) introduce a simulation software that models a conceptual factory. This software is specifically designed to support training courses for both students and workers. The goal is that they focus on learning how to analyse the modelled system. Haller et al. (2015) discuss the convenience of using port vehicle simulators to train ports personnel, as well as the difficulties to complete this training due to the elevated cost of high-quality port simulators.

In Mavinkurve and Patil (2016), the authors describe a case study related to the use of an electronic circuit simulator in their engineering courses. According to their study, the simulator helped students to increase their evaluation scores. Bach et al. (2017) give examples of how simulation games can be effectively integrated into management-related courses. Tao and Wu (2017) provide an extensive review of commercial simulation games, while Vlachopoulos and Makri (2017) analyse the influence of simulation games on higher education. In particular, they study how these tools can help students to achieve their learning objectives. Lawson and Leemis (2017) presents a simulation-education package for the $R$ statistical software. The authors propose to use the package in introductory simulation courses. Recognising the interdisciplinary importance of simulation, Ören et al. (2017) discuss the benefits of SE in STEM disciplines. These authors highlight the role of simulation as a tool for experiential learning and teaching via computer experiments that imitate real-life situations. Bruzzone and Massei (2017) analyse the challenges and opportunities that SE offers in military training and related areas. Leathrum Jr et al. (2018) propose increasing the cooperation between industrial and academic partners in order to develop simulation-based laboratories that enhance the training of students and prepare them better for their future professional activity. In their paper, they illustrate this concept with a simulation laboratory that allows students to test the performance of autonomous vehicles. McHaney (2018) introduces best practices regarding the use of SE in courses of cloud computing and big data. In the latter, for instance, students use simulation to generate large data sets on which they can test different data analytics techniques. Alsaadani and Bleil De Souza (2019) describe how universities are introducing SE to train architects in building performance. They consider some simulation-education examples from the literature and classify them into three different paradigms.

All in all, the previous review reveals a growing interest in the possibilities of SE as tool not just for teaching courses to students of STEM degrees but also to train managers and engineers from different industries and business.

\section{Serious games to enrich the learning experience}

As described in Mazur (2016), the learning process can be simplified in three main blocks -behaviour, cognition, and affect-, and a number of interrelations among them. For instance, it is well-known that cognitive levels benefit from positive emotional engagement with the learning subject. Turner et al. (2018) highlight how online serious games are valuable to reach better critical thinking skills and to improve the content knowledge. Moreover, affect-related aspects such as motivation level and self-esteem are also increased. In addition, serious games allow putting the player in realistic situations, where they can learn through experience and improve their decision-making abilities. Serious 
games should be designed in a way that they provide the required mechanics to reinforce the interrelations between behaviour, cognition, and affect, thus enriching the learning experience. The game, sometimes through a storyline, requires the player to conduct a number of actions that are clearly preestablished to achieve a given objective. The partial outputs will depend on the player's performance, and their decisions will result in different consequential scenarios. In addition, as indicated by Lamb et al. (2018), serious games should foster the emotional attachment to the outputs. Thus, the design of efficient serious games is not a straightforward task, and it requires a deep understanding of the underlying dynamics, and how they relate to the learning mechanics.

An efficient design of a serious game should guarantee that the level of demand by the player is compatible with his/her knowledge and skills, that is, challenging enough to provide the player a satisfactory feeling when achieving the goals, and affordable enough to prevent the player from discouraging and frustration. Thus, through progressing in the game as a result of the improved skills, tasks also become more complex. When this balance is reached, the level of engagement of the player is such that he/she is fully immersed in the learning process for a longer time period resulting in fewer distractions (Admiraal et al. 2011) and in a more effective content retention (Hainey et al. 2011). This state is known in Psychology as flow (Csikszentmihalyi 1997). Thus, serious games are an interesting tool to support the learning process once the content has been already presented in a more formal manner, e.g., through lectures (Rondon et al. 2013). Nevertheless, the entertainment elements of the game might distract the attention of students if the serious game is not adequately designed (Bellotti et al. 2011) or correctly presented to the students. Some studies note how learning the game mechanics adds an extra load to the students that eventually lose the main focus of the game (Ameerbakhsh et al. 2019). In fact, although both students and educators are becoming more comfortable with technology, (Jarvis 1995) notices the concern of some students when including this type of tool in the academic curricula. The benefits associated with the use of serious games in the learning environment are not always easy to measure, although a good analysis of these benefits is provided in Boyle et al. (2016). In some cases, the invested time in becoming familiar with the game might not compensate for the learning outcomes. For that reason, the game should be designed in collaboration with instructors, and further improvements conducted if needed based on a comprehensive analysis of the learning achievements in a validation process (Serrano-Laguna et al. 2018).

\section{Benefits of simulation-based education}

The proliferation of personal and portable computers along with the progress in hardware and software experienced during the last decades has boosted the use of simulationbased activities in higher-education programmes (Qudrat-Ullah 2010). The benefits of SE have been documented by different authors, among them, Shapira-Lishchinsky (2015) and Braghirolli et al. (2016). A summary is presented in Table 1 of the main benefits and drawbacks identified in the literature regarding the use of simulation and serious games in higher education. The table also includes some key references that discuss these benefits and drawbacks in detail.

Many documents describe experiences in which these benefits are illustrated. For instance, das Dores Cardoso et al. (2014) use SE in an automatic control course. They conclude that simulation allows students to gather hands-on experience and skills in 
Table 1 Summary of benefits and drawbacks related to the use of simulation-education tools

\begin{tabular}{|c|c|}
\hline Benefits & Drawbacks \& Limitations \\
\hline $\begin{array}{l}\text { Increased motivation for students Koh et al. (2010); } \\
\text { Klug and Hausberger (2009) }\end{array}$ & $\begin{array}{l}\text { Combination of entertainment and learning is not } \\
\text { immediate Pechenkina et al. (2017) }\end{array}$ \\
\hline $\begin{array}{l}\text { Emotional attachment to outcome due to the use of } \\
\text { a constructivist approach (Olfat et al. 2013; Connolly } \\
\text { et al. 2012) }\end{array}$ & $\begin{array}{l}\text { Games might distract from learning goals Rieber and } \\
\text { Noah (2008); Shelton and Scoresby (2011) }\end{array}$ \\
\hline $\begin{array}{l}\text { Construction of knowledge in safe environment } \\
\text { McManus and Rebentisch (2008); Ören et al. (2017) }\end{array}$ & $\begin{array}{l}\text { Some students and instructors might require special } \\
\text { training while working with these technologies } \\
\text { Keskitalo (2011); Ören et al. (2017) }\end{array}$ \\
\hline $\begin{array}{l}\text { Fosters collaborative work skills Chapman and Martin } \\
\text { (1995); Okuda et al. (2009); Shah et al. (2019) }\end{array}$ & $\begin{array}{l}\text { Difficulties to assess its effectiveness Girard et al. } \\
\text { (2013); Bellotti et al. (2013); Boyle et al. (2016) }\end{array}$ \\
\hline $\begin{array}{l}\text { Affective effects prior to cognitive processes } \\
\text { Vlachopoulos and Makri (2017) }\end{array}$ & $\begin{array}{l}\text { Some educators might be reluctant to } \\
\text { methodological changes (White 2017) }\end{array}$ \\
\hline $\begin{array}{l}\text { Fosters critical thinking, problem solving and decision } \\
\text { making Pirker and Gütl (2015); Tzimerman et al. (2014) }\end{array}$ & $\begin{array}{l}\text { Strong guidance might be required to avoid } \\
\text { disorganised knowledge Hauge and Riedel (2012); } \\
\text { Ören et al. (2017) }\end{array}$ \\
\hline
\end{tabular}

different realistic scenarios. In the area of operations management and finance, Curland and Lyn Fawcett (2001) conclude that SE facilitates the acquisition of quantitativeanalysis skills among students without a strong mathematical background. Regarding e-learning, Balci et al. (2013) point out the additional challenges associated with teaching modelling and simulation to online students. They also provide some recommendations to overcome these challenges. Actually, SE is clearly an ideal resource in many online courses due to its capacity to support the development of virtual laboratories (Grasas et al. 2013; Ceberio et al. 2016).

In the case of STEM programmes, simulation games make it possible for students to interact, in a safe environment, with models of real-life systems. Hence, students can develop their skills and acquire experience in the use of those systems that will encounter in their future professional careers. In most cases, only SE tools can provide students with these skills and experience. Hence, they constitute the perfect complement to theoretical lectures. In the area of revenue management, (Cleophas 2012) introduce a framework that facilitates the design of simulation games. As these authors state, simulation allows students to experience realistic variations in customers' demand and make the necessary corrective decisions without incurring costly mistakes. Examples illustrating the use of simulation-based games in education are abundant. For instance, Schäfer et al. (2013) propose the learning of logical concepts by using a collaborative-competitive simulation environment. Similarly, Rozhkova et al. (2016) describe an experience that involves the use of simulation-based games to learn algebra and geometry. These games cannot only be used for training purposes, but they can also include an evaluation component that provides feedback and scores to students.

\section{Case studies}

This section presents various case studies where serious games and simulation software have been implemented in different educational contexts. More precisely, the case of the University of Cantabria (Spain) is based on a traditional on-campus learning approach; the case of Universidade Aberta (Portugal) follows a pure online approach; while the case of the Universitat Autonoma de Barcelona (Spain) presents a blended approach. In addition, a fourth case regarding Trinity College Dublin (Ireland) has been included as well. It 
highlights some gender-related aspects to be considered when designing and implementing serious games and simulation software. Due to the present gender imbalance in the number of students in STEM studies, this last case is of special interest.

\section{A case study at the Universidad de Cantabria (Spain)}

The Universidad de Cantabria (www.unican.es) is a medium-sized university in Spain, with 12,000 registered students in graduate and undergraduate programs, mostly face-toface taught. Electronic Engineering and Electrical Engineering are two different degrees, however, some first-year subjects are jointly taught, such as introductory programming courses. In this context, during the academic year 2006/2007, 37 students of Electronic Engineering and 48 of Electrical Engineering used a serious game to learn C-language programming during the first year of the grade. The gender distribution was $80 \%$ male and $20 \%$ female. The used software, developed by Universitat Politecnica de Valencia (www.upv.es), can be adapted to the learning of different contents. The game features a story plot where a submarine must accomplish a certain rescue mission. Questions about $\mathrm{C}$-language programming are asked within the game, and the student must answer correctly for the submarine to keep advancing. In the first stage, the right answers are offered as feedback, so that the student can learn, or review previously learned contents. In the second stage, the student must answer further questions, however, the correct answers are not shown. In the third stage, there is an assessment within the game. The game was to be used as training for a test where the students should answer similar questions. However, the use of the game itself was not compulsory. The gaming had to be done by the student in an autonomous way, outside the classroom, using their own resources or the university's resources available for students. The instructor could be contacted on demand for any query.

Free direct feedback given by game players was positive but scarce, limited to only a small number of students. The use of this game was discontinued after one academic year, as no noticeable learning results were observed, as well as no general attitude of interest towards it. The lack of interest was likely related to the fact that the activity was not considered in the assessment of the course. The instructor's view is that gaming activity should be tutored inside the classroom in order to have any impact on learning. Alternatively, it should be integrated with an online learning environment such as Moodle, so that the instructor can track the students' activity and progress. We also believe the poor results might be assigned to the game mechanics itself, as it is not actually related to the contents being taught, but merely a container for questions and answers that could be used for any topic.

\section{A case study at the Universidade Aberta (Portugal)}

The Universidade Aberta (UAb, http://portal.uab.pt) is a pure on-line Portuguese university offering university degrees over the Internet to more than 8,000 students located in different continents. An adapted version of the well-known Moodle (https://moodle.org) platform for e-Learning is used in most of their courses. This case study analyses the Advanced Optimisation course in the Doctoral degree in Applied Mathematics and Modelling, during the time period from academic year 2015/2016 to 2018/2019 (4 academic years, one-course edition per year). All of the 5 to 8 students who take this module every year exhibit a strong background in Mathematics, although not all the students show a 
good background in programming and/or simulation concepts. Approximately $60 \%$ of them are male and $40 \%$ are female. Given that it is an online course, the students come from different Portuguese-speaking countries, such as Portugal, Brazil, Angola, etc. These students show a high degree of cultural heterogeneity and, of course, they live in different time zones, which explains why an asynchronous learning model is required.

In this course, students have to deal with complex decision-making problems that arise in real-life logistics, transportation, production, telecommunication, and financial systems. Most of these problems are large-scale and they include stochastic as well as dynamic components, which represent additional challenges for managers. During the course, students have to analyse different heuristic-based algorithms -implemented in programming languages, such as Java- that can effectively solve these problems in reasonable computing times. Simulation techniques are usually integrated inside the heuristic algorithm in order to deal with the real-life uncertainty that characterises some of these systems (Juan et al. 2015). Also, visual representations of the solutions generated by the algorithms are provided in order to obtain insights on how the different system components -e.g., distribution routes in a multi-depot environment- interact among them (Fig. 2).

According to the different information sources used, that is, students' scores, students' opinions in the online forums about their learning process, and instructors' view of the learning process, it can be concluded that the use of simulation techniques and the visual representation of the solutions generated by the optimization algorithms were key factors to enrich and extend the existing theoretical background of the students so that they could link mathematical formulations and concepts to real-life applications in different fields. Although students in the course enjoy the possibility of learning new solving approaches that can effectively support managers during complex decision-making processes, they also acknowledge the methodological

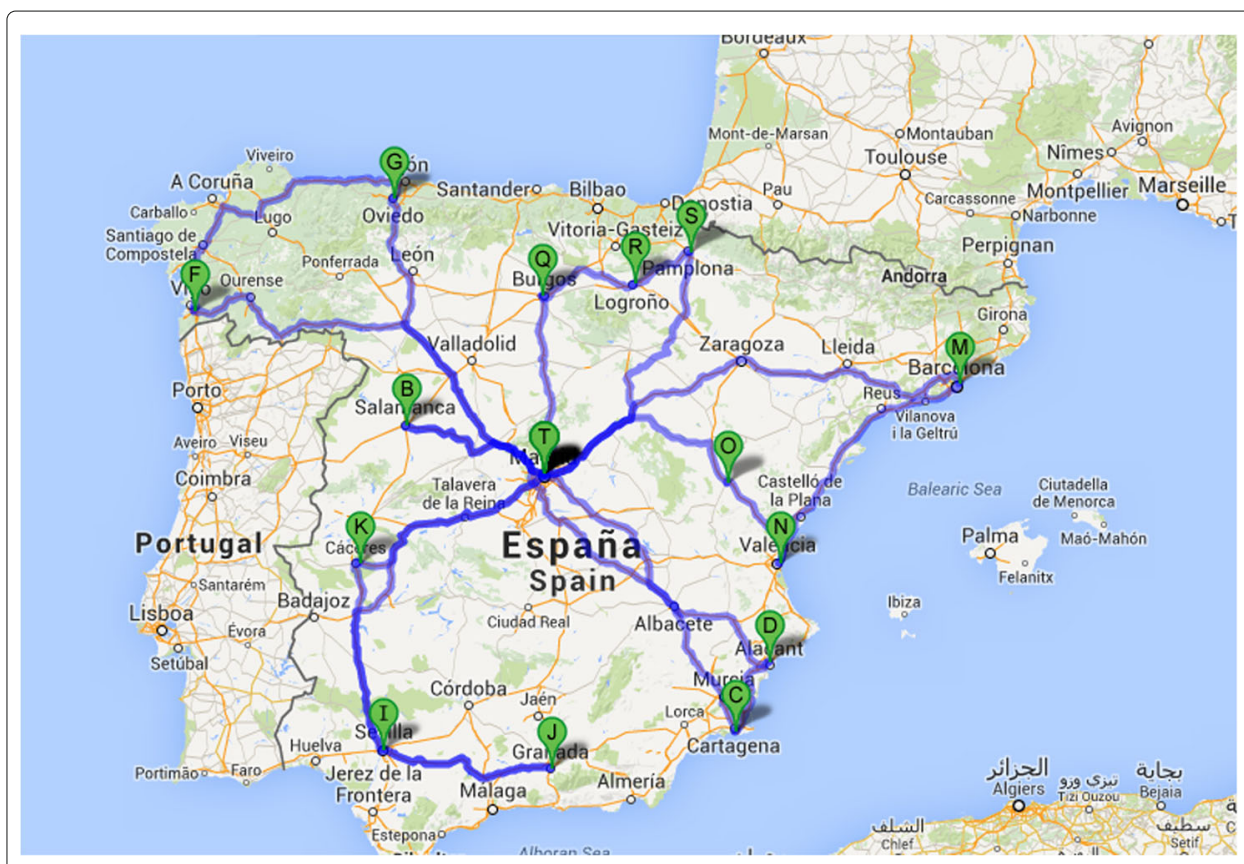

Fig. 2 Screen shot of a simulated solution to a logistics distribution problem 
challenges associated with the design and code implementation of such algorithms, which usually require interdisciplinary skills in different areas, i.e., optimisation concepts, advanced programming skills, and a good understanding of the specific application field (logistics, telecommunication, finance, etc.) as well as of the manager's utility function.

\section{A case study at the Universitat Autonoma de Barcelona (Spain)}

With over 30,000 registered students in more than 250 degrees (including both undergraduate and graduate programs), the Universitat Autonoma de Barcelona (UAB, http://www.uab.cat) is one of the largest and most prestigious universities in the area of Barcelona, Spain. Traditionally, UAB courses have been taught in a face-to-face modality. However, at present, the UAB also offers some degree programs which follow a blended learning paradigm via the support of online collaborative tools, such as Cisco WebEx (https://www.webex.com). Using this tool, students from any part of the world can follow the classes on-line and share their comments and questions with other students who are physically located inside the class where the instructor is lecturing.

One of these degrees is the UAB MSc in Aeronautical Management, which includes a course on theoretical and applied simulation. This case study analyses this master course, during the time period from the academic year 2013/2014 to 2018/2019 (6 academic years, one-course edition per year). The number of students per year ranges from 20 to 40 , from which $65-70 \%$ of the students follow the course in a face-to-face format, while the remaining 30-35\% follow the course online from South America. These students come with very different backgrounds, ranging from Aeronautical Management to Industrial Engineering or even Business Administration. About 70\% of the students are male, while the remaining $30 \%$ are female. This course contains a lab in which students are requested to use simulation software, such as Simio (https://www.simio.com) and Cast (https://airport-consultants.com) to model and analyse different scenarios in the context of airport and airlines management. For example, students can model a simple baggage handling system and monitoring how its performance evolves over time under different configurations (Fig. 3). By varying the components of the baggage handling system and the available resources, students can obtain insight on how the process work and make informed decisions about the right number of resources (assistants, vehicles, etc.) to be assigned during the check-in and transportation stages. Similar analysis can be performed on the security-control point, the boarding process (Mas et al. 2013; Carmona et al. 2014), the aircraft turn-around process (Silverio et al. 2013; San Antonio et al. 2017), the aircraft evacuation process (Estany et al. 2017), etc.

The possibility of using modern simulation software to build their own models of the real-life systems allow students to promote their creativity and modelling skills, as well as their understanding of how these systems work and how they can be improved (in terms of some key performance indicators) by choosing the right set up, as confirmed by students' scores, students' opinions in the online forums about their learning process, and instructors' view of the learning process during several years of interaction with the described simulation tools and concepts. Moreover, the fact that modern software benefits from the object-oriented paradigm also facilitates the development of complex simulation models by simply using drag-and-drop actions on an extensive library of objects. 


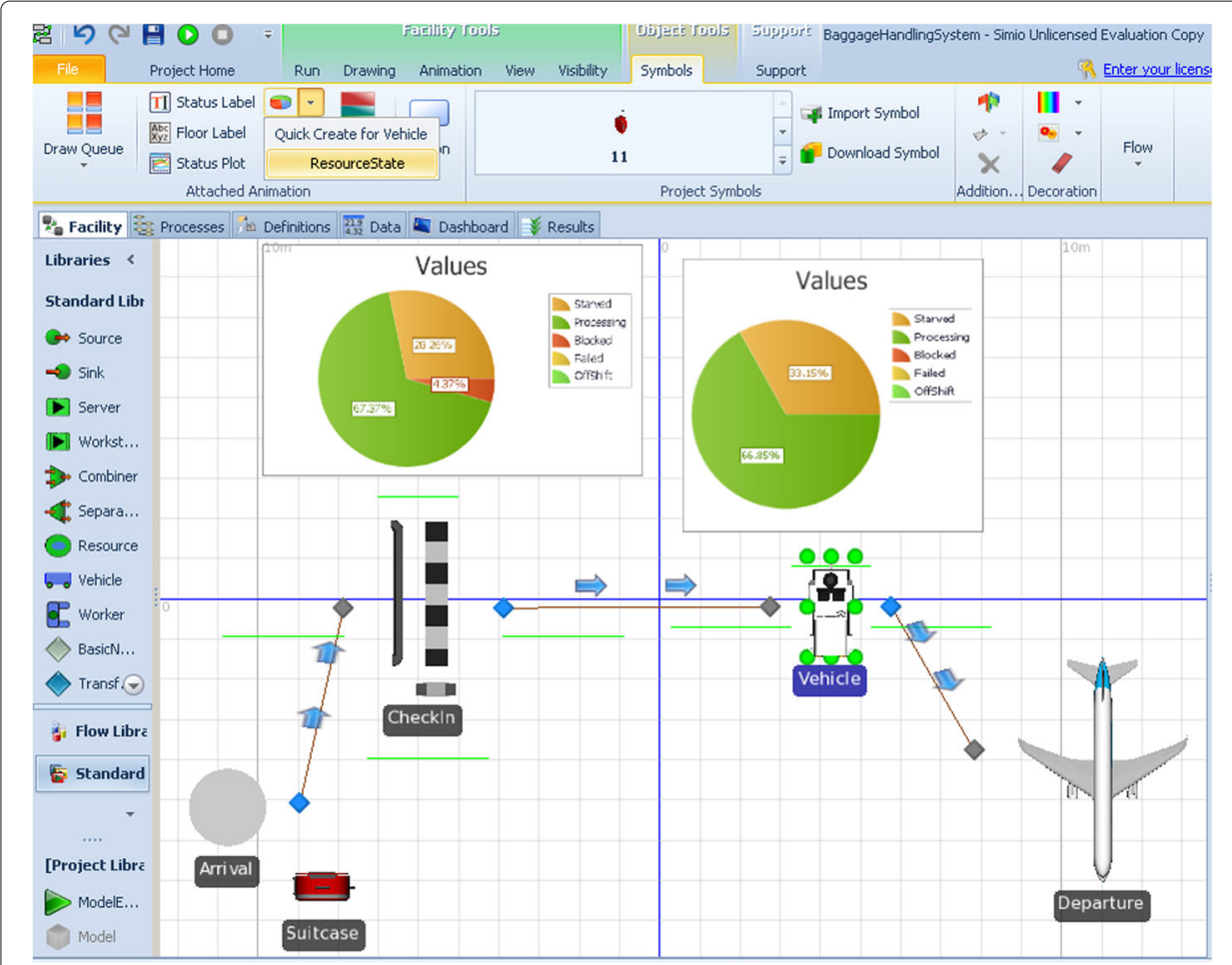

Fig. 3 Screen shot of a simple Simio model with monitoring graphs

\section{A case study at Trinity College Dublin (Ireland)}

Traditionally, the number of female students interested in Engineering degrees is low. In the case of Ireland, women constituted only about $12 \%$ of the new entrants to engineering courses in the academic year 2017-2018. With the aim of attracting their interest in the STEM careers, in the last years, Trinity College Dublin, (www.tcd.ie) has held 6weeks summer schools for groups of 10-15 female students of around 16 years old. Trinity College Dublin, with 17,000 undergraduate and postgraduate students, is ranked within the top 100 world universities in the 2017/2018 QS World University Ranking across all indicators. Within this context, the Department of Mechanical and Manufacturing Engineering developed and put into practice a tailor-made serious game for three years (2014-2017). The game is designed for the player to make a series of decisions required to manufacture hairdryers, e.g., the quantity to be manufactured, the selection of components considering aspects such as materials and suppliers, business strategies, etc. The main goal of the game is to show students specific job roles to enable them to envisage the type of work they might perform as engineers. The students' feedback collected by questionnaires showed that the most enjoyable diary activity in the summer school was the game, and in most of the cases, they continued playing at home. Nevertheless, further information about the capacity of the game to engage students in engineering careers has not been tracked.

When they designed the serious game, the mechanisms of cooperation and competition put in place were thoroughly considered given the different attitudes between male and female players, that is, women usually feel more comfortable cooperating than competing. In addition, students in pure competitive games do not benefit from the experiences 
and ideas of other colleagues. Nevertheless, competition is directly linked with the extrinsic motivation caused by a reward, as mentioned in "Introduction" section. An interesting element of the hairdryer manufacture game, which might have been the cause of its success in terms of popularity, is a newspaper where related pieces of news are released in a humorous tone. In addition, students can also release their own communications. This design component presents three advantages, i.e., to highlight the achievements of some players, which is related to the extrinsic motivation, to create the feeling of community, and to have fun, which both are related to the intrinsic motivation. In a second stage of the game, a more challenging version, requiring the application of engineering decisions is expected to be developed and used in the degree courses. The main goal is to avoid the loss of interest of students in the first years of Engineering, given the large content of foundation knowledge, without a straightforward application. Nevertheless, the development of the software is subjected to temporal and economic limitations, given that this type of activity is not seen as a priority, and there are not quantifiable indicators supporting their utility.

\section{Discussion}

Despite applied to different fields, target students and countries, the insights gained with each case seem to be consistent with the rest of the cases. In fact, recent literature addressing other case studies present well-aligned conclusions. For instance, like the cases of the Universidade Aberta and the Universitat Autonoma de Barcelona, Milosz and Milosz (2018) portray a case study in which simulation games are employed to train engineers in logistics-related concepts. Areas such as logistics, transport, and smart cities offer a clear environment where SE practices can be extremely useful in the training of new generations of decision-makers who do not necessarily have to certify a strong engineering background. Luna et al. (2018) tested the impact of integrating various learning strategies (i.e., simulation, serious games, case studies, and multimedia cases) in the curriculum of a Business Engineering course at the Universidad del Pacifico (Peru). Here, the use of simulation and serious games is guided by the instructors. They conclude that simulation games facilitate the development of students' analytical thinking, as discussed in the case study of the Universitat Autonoma de Barcelona.

In the field of marine ecology, Ameerbakhsh et al. (2019) used SE games to compare a student-centred (active) training approach with a teacher-led (passive) approach. The idea was to interact with a simulation game modelling a biomass production system. Then, by properly setting this model, the goal was to increase the sustainability of the marine environment. The study concluded that the participation of an expert instructor could significantly enrich the experience of the students with the simulation model and guide them better during their learning process. These results reinforce the idea that the instructor's support and guidance add value to the simulation-supported training process, as observed in the case study of the Universidad de Cantabria. Also, this conclusion is supported by Luna et al. (2018), who emphasises the fact that serious games need to provide goal-focused challenges for the users, and that the users should receive informative feedback from both the game and the instructor.

Many works mention the enjoyable learning experience and how the students feel more motivated when simulation and serious games are incorporated in their academic curricula, as highlighted in the case of Trinity College Dublin. Nevertheless, the adequate 
engagement of the students with these tools might require the recognition of the effort and time invested when students are assessed. In addition, they also contribute to reducing the gap between theory and practice, which in some STEM areas might be quite noticeable. This feature underpins the work of Reis and Kenett (2017), who present a set of storyboards to illustrate the potential of simulation in higher education when training students in a number of statistical methods.

\section{Conclusions and future work}

In areas such as engineering, science, technology, mathematics, and management, new generations of employees will require to deal with increasingly complex systems in their daily activities. Among many others, some examples of these systems are telecommunication networks, distributed computer systems, supply chains, civil infrastructure networks, transportation systems, etc. These systems are not only characterised by their large scale and the number of interactions among their components, but also by their levels of uncertainty and dynamism. Hence, it becomes necessary to train students accordingly and provide them with the analytical skills that they will need when designing, implementing, and using these systems. Simulation education software, tools, and games constitute an excellent methodological option to support instructors during the training process since simulation allows for realistic models that students can employ during their learning activities.

Among the many benefits provided by simulation education resources, their easy integration within blended and online courses is a remarkable fact that promotes their expansion and popularity among universities and training centres worldwide. In effect, simulation-based labs can be used by students located in different countries, universities, and degrees. This in turn facilities the development of interdisciplinary skills, teamwork abilities, and multi-cultural learning processes. Hence, we can think about simulation education as not only a popular educational resource, but as one that will still increase its presence in modern degrees curricula.

The following research lines are aimed to be explored in the future; $(i)$ an analysis of how simulation education tools are currently being used in blended and online education; and (ii) a discussion on how simulation education can also contribute to enhancing the learning and teaching experience in interdisciplinary master courses, where students show different backgrounds and skills.

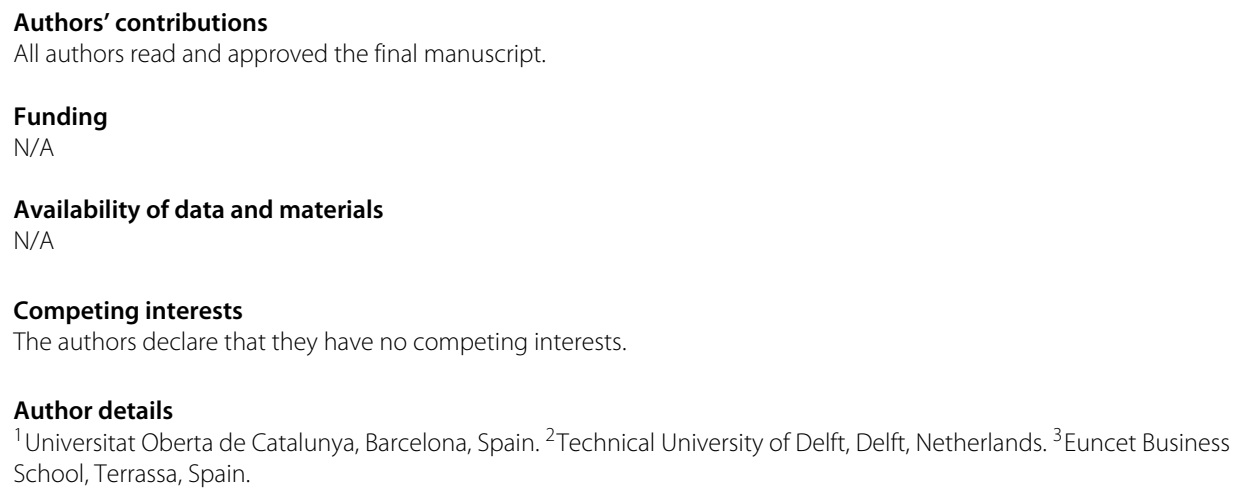




\section{References}

Admiraal, W., Huizenga, J., Akkerman, S., \& Ten Dam, G. (2011). The concept of flow in collaborative game-based learning. Comput. Hum. Behav., 27, 1185-1194.

Alnoukari, M., Shafaamry, M., Aytouni, K., \& Damascus, S. (2013). Simulation for computer sciences education. Commun. ACS, 6, 1-19.

Alsaadani, S., \& Bleil De Souza, C. (2019). Performer, consumer or expert? a critical review of building performance simulation training paradigms for building design decision-making. J. Build. Perform. Simul., 12, 289-307.

Ameerbakhsh, O., Maharaj, S., Hussain, A., \& McAdam, B. (2019). A comparison of two methods of using a serious game for teaching marine ecology in a university setting. Int. J. Hum. Comput. Stud., 127, 181-189.

Avramenko, A. (2012). Enhancing students' employability through business simulation. Educ. Train., 54, 355-367.

Bach, M.P., Zoroja, J., \& Fašnik, M. (2017). Teaching Business Simulation Games: Preliminary Current Practice Overview. In E. Tome, G. Neumann, B. Knezevic (Eds.) Proceedings of the International Conference: Theory and Applications in the Knowledge Economy (pp. 432-443). Lisbon: Eduardo Tome.

Balci, O., Deater-Deckard, K., \& Norton, A. (2013). Challenges in teaching modeling and simulation online. In Proceedings of the 2013 Winter Simulation Conference: Simulation: Making Decisions in a Complex World (pp. 3568-3575). New Jersey: IEEE Press. https://doi.org/10.1109/WSC.2013.6721718.

Becker, L.R., \& Hermosura, B.A. (2019). Simulation education theory. In Comprehensive Healthcare Simulation: Obstetrics and Gynecology (pp. 11-24): Springer.

Bellotti, F., Kapralos, B., Lee, K., Moreno-Ger, P., \& Berta, R. (2013). Assessment in and of serious games: an overview. Adv. Hum. Comput. Interact., 2013,1.

Bellotti, F., Ott, M., Arnab, S., Berta, R., de Freitas, S., Killi, K., ... De Gloria, A. (2011). Designing serious games for education: from pedagogical principles to game mechanisms. In Proceedings of the 5 th European Conference on Games Based Learning. University of Athens, Greece (pp. 26-34). Reading, UK: Academic Publishing Limited.

Bojičić-Petrov, I., Simić, D., \& MacKinnon, R.J. (2012). Simulation education: A review of the current status. Serbian J. Anesth. Intensive Ther., 34, 177-183.

Boyle, E.A., Hainey, T., Connolly, T.M., Gray, G., Earp, J., Ott, M., ...Pereira, J. (2016). An update to the systematic literature review of empirical evidence of the impacts and outcomes of computer games and serious games. Comput. Educ., 94 , 178-192.

Braghirolli, L.F., Ribeiro, J.L.D., Weise, A.D., \& Pizzolato, M. (2016). Benefits of educational games as an introductory activity in industrial engineering education. Comput. Hum. Behav., 58, 315-324.

Bruzzone, A.G., \& Massei, M. (2017). Simulation-based military training. In Guide to Simulation-Based Disciplines (pp. 315-361). Cham: Springer International Publishing. https://doi.org/10.1007/978-3-319-61264-5_14.

Cai, Y., Goei, S.L., \& Trooster, W. (2016). Simulation and serious Games for education. Singapore: Springer.

Cant, R.P., \& Cooper, S.J. (2017). Use of simulation-based learning in undergraduate nurse education: An umbrella systematic review. Nurse Educ. Today, 49, 63-71.

Carmona, G., Juan, A.A., \& Fonseca, P. (2014). Optimization of aircraft boarding processes considering passengers' grouping characteristics. In Proceedings of the 2014 Winter Simulation Conference (pp. 1977-1988): IEEE Press. https:// doi.org/10.1109/wsc.2014.7020044.

Ceberio, M., Almudí, J.M., \& Franco, A. (2016). Design and application of interactive simulations in problem-solving in university-level physics education. J. Sci. Educ. Technol., 25, 590-609.

Chapman, G., \& Martin, J. (1995). Computerized business games in engineering education. Comput. Educat., 25, 67-73.

Cleophas, C. (2012). Designing serious games for revenue management training and strategy development. In roceedings Title: Proceedings of the 2012 Winter Simulation Conference (WSC): IEEE. https://doi.org/10.1109/wsc.2012.6465154.

Connolly, T.M., Boyle, E.A., MacArthur, E., Hainey, T., \& Boyle, J.M. (2012). A systematic literature review of empirical evidence on computer games and serious games. Comput. Educ., 59, 661-686.

Costantino, F., Di Gravio, G., Shaban, A., \& Tronci, M. (2012). A simulation based game approach for teaching operations management topics. In Proceedings of the 2012 Winter Simulation Conference (WSC) (pp. 1-12): IEEE. https://doi.org/10. 1109/wsc.2012.6465028.

Csikszentmihalyi, M. (1997). Flow and the psychology of discovery and invention. vol. 39. New York.

Curland, S.R., \& Lyn Fawcett, S. (2001). Using simulation and gaming to develop financial skills in undergraduates. Int. J. Contemp. Hosp. Manag., 13, 116-119.

Deshpande, A.A., \& Huang, S.H. (2011). Simulation games in engineering education: a state-of-the-art review. Comput. Appl. Eng. Educ., 19, 399-410.

das Dores Cardoso, L., de Assis Rangel, J.J., Nascimento, A.C., Laurindo, Q.M.G., \& Camacho, J.C. (2014). Discrete event simulation for teaching in control systems. In Proceedings of the Winter Simulation Conference 2014: IEEE. https://doi. org/10.1109/wsc.2014.7020190.

Estany, P., Calvet, L., Juan, A.A., \& Fonseca, P. (2017). Using simulation to estimate evacuation times in large-size aircrafts: A case study with simio. In 2017 Winter Simulation Conference (WSC): IEEE. https://doi.org/10.1109/wsc.2017.8248050

Faria, A.J., Hutchinson, D., Wellington, W.J., \& Gold, S. (2009). Developments in business gaming: A review of the past 40 years. Simul. Gaming, 40, 464-487.

Frantzén, M., \& Ng, A.H. (2015). Production simulation education using rapid modeling and optimization: Successful studies. In 2015 Winter Simulation Conference (WSC) (pp. 3526-3537): IEEE. https://doi.org/10.1109/wsc.2015.7408512.

Gagne, R.M., Wager, W.W., Golas, K.C., Keller, J.M., \& Russell, J.D. (2005). Principles of instructional design. Perform. Improv. $44,44-46$.

Girard, C., Ecalle, J., \& Magnan, A. (2013). Serious games as new educational tools: how effective are they? a meta-analysis of recent studies. J. Comput. Assist. Learn., 29, 207-219.

Grasas, A., Ramalhinho, H., \& Juan, A.A. (2013). Operations research and simulation in master's degrees: a case study regarding different universities in spain. In 2013 Winter Simulations Conference (WSC): IEEE. https://doi.org/10.1109/ Wsc.2013.6721722.

Gruler, A., De Armas, J., Juan, A.A., \& Goldsman, D. (2019). Modelling human network behaviour using simulation and optimization tools: the need for hybridization. SORT-Statistics and Operations Research Transactions, 193-222. https:// doi.org/10.2436/20.8080.02.85. 
Hainey, T., Connolly, T.M., Stansfield, M., \& Boyle, E.A. (2011). Evaluation of a game to teach requirements collection and analysis in software engineering at tertiary education level. Comput. Educ., 56, 21-35.

Haller, A., Putz, L.-M., \& Schauer, O. (2015). Transhipment simulators for training of ports' personnel. Adv. Eng. Forum, 13, $277-281$.

Hauge, J.B., \& Riedel, J.C. (2012). Evaluation of simulation games for teaching engineering and manufacturing. Procedia Comput. Sci., 15, 210-220.

Jarvis, P. (1995). Adult and continuing education: theory and practice. London and New York: Psychology Press.

Juan, A.A., Faulin, J., Grasman, S.E., Rabe, M., \& Figueira, G. (2015). A review of simheuristics: extending metaheuristics to deal with stochastic combinatorial optimization problems. Oper. Res. Perspect., 2, 62-72.

Juan, A.A., Loch, B., Daradoumis, T., \& Ventura, S. (2017). Games and simulation in higher education. Int. J. Educ. Technol. High. Educ., 14, 37.

Keskitalo, T. (2011). Teachers' conceptions and their approaches to teaching in virtual reality and simulation-based learning environments. Teach. Teach. Theory Pract., 17, 131-147.

Klug, M., \& Hausberger, P. (2009). Motivaton of students for futher education in simulation by an applied example in a related other course in engineering education: a case study. In Proceedings of the 2009 Winter Simulation Conference (WSC): IEEE. https://doi.org/10.1109/wsc.2009.5429330.

Koh, C., Tan, H.S., Tan, K.C., Fang, L., Fong, F.M., Kan, D., ... Wee, M.L. (2010). Investigating the effect of 3d simulation based learning on the motivation and performance of engineering students. J. Eng. Educ., 99, $237-251$.

Kutz, J.N., Brunton, S.L., Brunton, B.W., \& Proctor, J.L. (2016). Dynamic mode decomposition: data-driven modeling of complex systems. Philadelphia: Society for Industrial and Applied Mathematics.

Lamb, R.L., Annetta, L., Firestone, J., \& Etopio, E. (2018). A meta-analysis with examination of moderators of student cognition, affect, and learning outcomes while using serious educational games, serious games, and simulations. Comput Hum. Behav., 80, 158-167.

Lawson, B., \& Leemis, L.M. (2017). An r package for simulation education. In 2017 Winter Simulation Conference (WSC): IEEE. https://doi.org/10.1109/wsc.2017.8248124.

Leathrum Jr, J.F., Mielke, R.R., Shen, Y., \& Johnson, H. (2018). Academic/industry educational lab for simulation-based test \& evaluation of autonomous vehicles. In 2018 Winter Simulation Conference (WSC): IEEE. https://doi.org/10.1109/wsC. 2018.8632548.

Luna, A., Chong, M., \& Jurburg, D. (2018). Learning strategies to optimize the assimilation of ITC2 competencies for business engineering programs. In 2018 IEEE International Conference on Teaching, Assessment, and Learning for Engineering (TALE): IEEE. https://doi.org/10.1109/tale.2018.8615444.

Martin, D., \& McEvoy, B. (2003). Business simulations: a balanced approach to tourism education. Int. J. Contemp. Hosp. Manag., 15, 336-339.

Mas, S., Juan, A.A., Arias, P., \& Fonseca, P. (2013). A simulation study regarding different aircraft boarding strategies. In Modeling and Simulation in Engineering, Economics, and Management (pp. 145-152): Springer Berlin Heidelberg. https://doi.org/10.1007/978-3-642-38279-6_16.

Mavinkurve, M., \& Patil, M. (2016). Impact of simulator as a technology tool on problem solving skills of engineering students-a study report. J. Eng. Educ. Transform., 29, 124-131.

Mazur, J.E. (2016). Learning Behavior. New York: Routledge.

McHaney, R. (2018). Simulation education in non-simulation courses. In 2018 Winter Simulation Conference (WSC) (pp. 4038-4045): IEEE. https://doi.org/10.1109/wsc.2018.8632361.

McManus, H., \& Rebentisch, E. (2008). Experiences in simulation-based education in engineering processes. In 200838 th Annual Frontiers in Education Conference: IEEE. https://doi.org/10.1109/fie.2008.4720679.

Milosz, M., \& Milosz, E. (2018). Computer decision simulation games for logistic training of engineers. In 2018 IEEE Global Engineering Education Conference (EDUCON): IEEE. https://doi.org/10.1109/educon.2018.8363233.

Montgomery, D.C., Jennings, C.L., \& Kulahci, M. (2015). Introduction to time series analysis and forecasting. Hoboken: Wiley.

Nance, R.E. (2000). Simulation education: Past reflections and future directions. In Proceedings of the 2000 Winter Simulation Conference (pp. 1595-1601). Piscataway: IEEE Press. https://doi.org/10.1109/WSC.2000.899144.

Okuda, Y., Bryson, E.O., DeMaria Jr, S., Jacobson, L., Quinones, J., Shen, B., ... Levine, A.I. (2009). The utility of simulation in medical education: what is the evidence?. Mt Sinai J. Med. J. Trans. Personalized Med., 76, 330-343.

Olfat, M., Paddrik, M.E., Hayes, R., \& Wold, K. (2013). Revolutionizing financial engineering education: Simulation-based strategies for learning. Available at SSRN https://ssrn.com/abstract=2197542. https://doi.org/10.2139/ssrn.2197542.

Ören, T., Turnitsa, C., Mittal, S., \& Diallo, S.Y. (2017). Simulation-based learning and education: Springer.

Pasin, F., \& Giroux, H. (2011). The impact of a simulation game on operations management education. Comput. Educ., 57, $1240-1254$.

Pechenkina, E., Laurence, D., Oates, G., Eldridge, D., \& Hunter, D. (2017). Using a gamified mobile app to increase student engagement, retention and academic achievement. Int. J. Educ. Technol. High. Educ., 14, 31.

Perera, T., \& Rupasinghe, T. (2015). Teaching supply chain simulation: from beginners to professionals. In 2015 Winter Simulation Conference (WSC) (pp. 3548-3556): IEEE. https://doi.org/10.1109/wsc.2015.7408514.

Pirker, J., \& Gütl, C. (2015). Educational gamified science simulations. In Gamification in Education and Business (pp. 253-275): Springer. https://doi.org/10.1007/978-3-319-10208-5_13.

Qudrat-Ullah, H. (2010). Perceptions of the effectiveness of system dynamics-based interactive learning environments: An empirical study. Comput. Educ., 55, 1277-1286.

Reis, M., \& Kenett, R.S. (2017). A structured overview on the use of computational simulators for teaching statistical methods. Qual. Eng., 29, 730-744.

Rieber, L.P., \& Noah, D. (2008). Games, simulations, and visual metaphors in education: antagonism between enjoyment and learning. Educ. Media Int., 45, 77-92.

Riley, G.F. (2012). Using network simulation in classroom education. In Proceedings of the 2012 Winter Simulation Conference (WSC): IEEE. https://doi.org/10.1109/wsc.2012.6465290.

Rondon, S., Sassi, F.C., \& de Andrade, C.R.F. (2013). Computer game-based and traditional learning method: a comparison regarding students' knowledge retention. BMCMed. Educ., 13, 30. 
Rozhkova, S., Rozhkova, V., \& Chervach, M. (2016). Introducing smart technologies for teaching and learning of fundamental disciplines. In Smart Education and e-Learning 2016 (pp. 507-514): Springer. https://doi.org/10.1007/9783-319-39690-3_45.

San Antonio, A., Juan, A.A., Calvet, L., Fonseca, P., \& Guimarans, D. (2017). Using simulation to estimate critical paths and survival functions in aircraft turnaround processes. In 2017 Winter Simulation Conference (WSC): IEEE. https://doi.org/ 10.1109/wsc.2017.8248055.

Schäfer, A., Holz, J., Leonhardt, T., Schroeder, U., Brauner, P., \& Ziefle, M. (2013). From boring to scoring-a collaborative serious game for learning and practicing mathematical logic for computer science education. Comput. Sci. Educ., 23, $87-111$.

Schild, E. (1968). Simulation games in learning. Thousand Oaks: Sage Publications, Inc.

Serrano-Laguna, Á., Manero, B., Freire, M., \& Fernández-Manjón, B. (2018). A methodology for assessing the effectiveness of serious games and for inferring player learning outcomes. Multimed. Tools Appl., 77, 2849-2871.

Shah, A., Mai, C.L., Shah, R., \& Levine, A.I. (2019). Simulation-based education and team training. Otolaryngol. Clin. N. Am., 52, 995-1003.

Shapira-Lishchinsky, O. (2015). Simulation-based constructivist approach for education leaders. Educ. Manag. Adm. Leadersh., 43, 972-988.

Shelton, B.E., \& Scoresby, J. (2011). Aligning game activity with educational goals: Following a constrained design approach to instructional computer games. Educ. Technol. Res. Dev., 59, 113-138.

da Silva, R.J.R., Rodrigues, R.G., \& Leal, C.T.P. (2019). Gamification in management education: A systematic literature review. BAR-Braz. Adm. Rev., 16(2). https://doi.org/10.1590/1807-7692bar2019180103.

Silverio, I., Juan, A.A., \& Arias, P. (2013). A simulation-based approach for solving the aircraft turnaround problem. In Modeling and Simulation in Engineering, Economics, and Management (pp. 163-170): Springer Berlin Heidelberg. https://doi.org/10.1007/978-3-642-38279-6_18.

Stanley, D., \& Latimer, K. (2011). The Ward': a simulation game for nursing students. Nurse Educ. Pract., 11, 20-25.

Tao, Y.-H., \& Wu, W.-N. (2017). Supplementing the review of business simulation games via bibliometrics analysis. In Proceedings of the 4th Multidisciplinary International Social Networks Conference on ZZZ - MISNC'17: ACM Press. https:// doi.org/10.1145/3092090.3092107.

Turner, P.E., Johnston, E., Kebritchi, M., Evans, S., \& Heflich, D.A. (2018). Influence of online computer games on the academic achievement of nontraditional undergraduate students. Cogent Educ., 5, 1437671.

Tvrdoň, L., \& Jurásková, K. (2015). Teaching simulation in logistics by using witness and captivate software. Procedia Soc. Behav. Sci., 174, 4083-4089.

Tzimerman, A., Dery, L., Balouka, N., Cohen, I., Herer, Y., \& Shtub, A. (2014). Simulation-based education in supply chain and project management. In Bridging Data and Decisions (pp. 138-160): INFORMS. https://doi.org/10.1287/educ.2014.0127.

Vlachopoulos, D., \& Makri, A. (2017). The effect of games and simulations on higher education: a systematic literature review. Int. J. Educ. Technol. High. Educ., 14, 22.

White, M. (2017). Keep calm and simulate on: Faculty experiences and insights into implementing best practices in simulation. Teach. Learn. Nurs., 12, 43-49.

\section{Publisher's Note}

Springer Nature remains neutral with regard to jurisdictional claims in published maps and institutional affiliations.

\section{Submit your manuscript to a SpringerOpen ${ }^{\odot}$ journal and benefit from:}

- Convenient online submission

- Rigorous peer review

- Open access: articles freely available online

- High visibility within the field

- Retaining the copyright to your article

Submit your next manuscript at $\boldsymbol{\triangleright}$ springeropen.com 